\title{
Primary Exploration on the Construction of University Laboratory Culture under the Background of "Double First-rate"
}

\author{
Dang Yao-jia \\ School of Education Tianjin University \\ Hebei, China \\ E-mail: tju_dyj@163.com
}

\author{
Zhu Hong-chun \\ School of Education Tianjin University \\ Tianjin, China \\ E-mail: 553029860@qq.com
}

\begin{abstract}
The aim of the study is to explore the construction of laboratory culture in order to achieve the goal of "Double First-rate" construction. This paper illustrated the great importance of constructing laboratory culture under the background of "Double First-rate". It analyzed the problems in the current laboratory culture construction, which were inadequate attention paid to its importance, inadequate role played in educational function, lack of internal innovative culture and so on. Based on this, it suggested that the universities should attach great importance to the laboratory culture construction, exert the educational function of the laboratory culture construction, firmly establish the laboratory innovation and cultural foundation so as to provide soft power guarantee for creating first-class laboratory and enhancing "Double First-rate" construction.
\end{abstract}

Keywords-laboratory; laboratory culture construction "Double First-rate"; first-class laboratory

\section{INTRODUCTION}

In order to further improve China's higher education level, strengthen national core competence and lay foundation of long-term development, the State Council has printed and distributed "Overall Plan for Promotion Construction of the World-class Universities and First-class Discipline" (simplified as "Overall Plan" in the following thesis). The Overall Plan precisely points out that take the construction of world leading universities and first-class disciplines, i.e. the "Double Firstclass", as the development strategy that China's higher education may face under the new situation and task [1]. The laboratory plays an important role in transferring all these factors integrating. One of the most essential conditions of becoming world leading universities is building first-class lab, it is a platform that can promote the interdisciplinary development. To achieve the constructive target of "Double First-class" Initiative, China's higher education must create a series of top-ranking labs. It is far away from the first-class labs construction if just concern about the hard power like human resources, financial resources, and material resources. A kind of mighty power is also needed to condensing all aspects of labs into resultant force, which is rooted in the soft power of lab construction-cultural construction. As one of the important content of lab construction, laboratorial culture provides precious spiritual wealth and incessant impetus for the development of labs. By carrying forward the building of university laboratorial culture, it is beneficial to form top university spirit, improve the quality and level of talent cultivation, create university brand characteristics, and promote the competence of universities in "Double First-class" Initiative Therefore, under the circumstance of "Double First-class", how to form a kind of lab culture that share the same strain as firstclass university spirit has become an essential research content in building of first-rate labs and promoting China's higher education reform and development.

\section{THE MEANING OF BUILDING UNIVERSITY LABORATORIAL CULTURE UNDER THE CIRCUMSTANCE OF "DOUBLE- FIRST-CLASS"}

Laboratorial culture is a kind of interior laboratory group culture, which is promoted and formed during the process of building and developing of lab by the joint effort of successive lab members. It included the following four parts: firstly, material culture consists of external environment such as architectural composition, decorative ornaments, characteristic design and so on; secondly, the organization rules that keep the lab operating as well as system and management culture formed with institutional norm; thirdly, spiritual culture, i.e. the values, ideal and faith, moral quality of lab members; fourthly, behavior culture, including academic atmosphere, interpersonal relationship and behavioral pattern.

Take a panoramic view of the world-class labs, they all possess excellent laboratorial culture. First-class spiritual culture is the primary cause of a series of top-rankings, which support and produce the best talents, first-rate scientific achievements and big-league social contribution [2]. For example, Cavendish Laboratory is called as "the nursery garden of talents", Bell Laboratory is rewarded as "the Garden of Eden of researches", they are famous all over the world for their active thoughts and well scholarship circumstances [3]. Thus, the realization of building first-class labs needs to permeate excellent culture into each aspect of lab construction. Changing people through knowledge, and cultivate highquality and high-level comprehensive innovative personnel, in order to produce sophisticated and technical original scientific research achievements. Laboratorial culture construction can 
rouse the interior development vitality and improve the comprehensive competitiveness of labs, which aims at building excellent labs. Specifically speaking, there are three important functions of building laboratorial culture under the circumstances of "Double First-class".

\section{A. To the Benefit of the Sustainable Development of University Labs}

Under the circumstances of "Double First-class", one of the key features of first-class labs is provided with the ability of sustainable development. Laboratorial culture is the essential support for labs to achieve their sustainable development. First of all, laboratorial culture is good for shaping favorable team spirit. It is a kind of strength of character that formed and deposited during the long process of work and study by lab members [4]. Through building harmonious atmosphere, it strengthens the sense of belonging, identity and pride of lab members, produces strong cohesive force, centripetal force and infectious force, forms close synergetic win-win relationship, and finally promotes the whole level of labs in cooperation and benign competition. Then, laboratorial culture is in favor of enhancing experimental teaching and academic scientific research level. By means of specific material carriers and the attitude of scholarly research, laboratorial culture can form well research ethos, and motivate the sense of mission about scientific research from interior aspect as well as the strong desire of consistently pursuing truth. What's more, laboratorial culture provides a new viewpoint to promote management level. Labs can combine the flexible strength with system management and easily covert it to the model of "humanization" system management. It is beneficial to respect the dominant role and character of individual, stimulate the interior development motivation of lab members, and facilitate innovative thinking. At the same time, cultural management is capable of adapting all kinds of new condition and fluxion, thus may cover the shortage of hysteresis nature in system management. Therefore, excellent laboratorial culture may permeate into various aspects of lab construction as well as individual thinking and behavior, providing deep spiritual motivation for lab development and achieving the sustainable development of laboratory.

\section{B. To the Benefit of Forming World-class University}

The Overall Plan points out that "reinforce university cultural development, strengthen the cultural selfconsciousness and institutional confidence, form respectively characteristic world-class spirit and university culture to promote social progress and guide cultural process is one of the important construction mission of "Double First-class" Initiative [5]. Laboratorial culture has an essential influence in promoting the formation and growth of world-class culture. On the one hand, laboratorial culture inherits university culture, because without the nutrition of university's spiritual land, the former can't form and develop. They come down in the same strain. As a subsystem of university culture, laboratorial culture intensively reflects the scholarship feature as well as state and style of university and spreads the spiritual peculiarity of university, providing specific operation methods for holding together the university spirit and compacting university cultural connotation. On the other hand, laboratorial culture innovates university culture. It is the basic carrier of practicing university culture, with the advantages in independence, talent and platform of cultural innovation. It owns the autonomy, motility and guidance quality in developing university culture. Building characteristic interior lab culture may deepen the spiritual ethos of university and enrich the cultural connotation of university. The construction of university lab culture is an important practice of discovering the cultural formation of world-class university, with the function of providing available methods for promoting the construction of university culture and its system.

\section{To the Benefit of the Cultivation of Top Innovative Talents}

The ultimate goal of building laboratorial culture is to achieve educating people through laboratorial culture. It refers to a process that during the course of inheriting and innovating the culture, leading the whole members to choose correct values thus the group culture will transfer into individual culture, in order to realize unceasing self-improvement and self-transcendence of individual moral quality, culture and knowledge. Under the requirement of "Double First-class", lab culture will provide key strength to the cultivation of top innovative talents. First, excellent lab culture may greatly respect and release the independent character and ideology through creating easy and free academia and also placatory atmosphere. Integrating the innovative culture into lab culture system and creating an environment that encouraging innovation both home and abroad, is beneficial to the emergence of innovative thinking and spirit, as well as a growing condition for cultivating innovative talents. Second, cultural construction can forge people's thoughts, ideology, character, emotions and behaviors deeply by the strength of culture and have a long and prolong impact on individual throughout their life. Laboratorial culture emphasizes utilizing the externalization and internalization of spiritual strength to lead the generation of cognition, emotion and behavior, and at the same time enable its inherent uniformity. Lab culture can permeate into each aspect of lab construction, for instance, easy and comfortable external environment, rigorous teaching attitude in scientific research, rich cultural atmosphere and so on. All these are not only in favor of lab members to acquire knowledge theory and practice ability, to form rigorous scientific research attainment, but also strengthen the experience of positive emotions for those members, remodel their value pursuing, individual basic attitude of scholarship and knowledge cognition and conducting themselves, and promoting the comprehensive quality of university talents.

\section{THE PROBLEMS EXISTING DURING BUILDING OF UNIVERSITY LABORATORIAL CULTURE UNDER THE CIRCUMSTANCE OF "DOUBLE- FIRST-CLASS"}

With the reform and development of higher education, China has increases the funding of university labs, esp. key labs, thus the hardware equipment of lab construction has improved a lot. However, the promotion of labs' independent innovative ability is still in a dilemma to shape a highly effective innovative system; the demission of some core members in lab or undertake transfer of personnel has hindered the long-term stable development of labs; some labs are previously equivalent in manpower, financial and material 
resources are gradually far from each other after a period of development [6]. Those phenomena all suggest that there existing certain problems in the contemporary context of university laboratorial culture construction, which restricts the realization of building first-class labs and affects the goal of "Double First-class" Initiative.

\section{A. Pay Little Attention to the Laboratorial Culture}

Recent years, the hardware configuration and external equipment in China's university labs have greatly satisfied the requirement of experimental teaching and scientific researches, accelerated the promotion of transformational output of scientific efforts, and realizing the conversion from small and professional to comprehensive and open models [7]. The construction of university labs has generally made some achievements, while the cultural construction is still weak, i.e. in a relatively inferior position. On the cognition level of laboratorial culture, lab members are lacking a clear understanding of connotation, correct recognition of features, accurate control of functions, and they even failed to realize the essential role that lab culture played in the promotion of building the world-class labs. It results in that laboratorial cultural construction is always the weak and can't be truly brought into the construction of labs. On the practical level, some lab members did a few of relative constructional trails but they haven't taken integrated form of laboratorial cultural system. For example, some people regarded putting green plants as the whole content of lab's external environmental construction, and holding entertainment activities as the only symbol of lab culture. They all failed to fully explore the potential of laboratorial cultural soft power in the building of first-class labs.

\section{B. Insufficient Education Function of Laboratorial Culture}

Top ranking innovative talents are the main force of building the "Double first-class" Initiative. Educating people through lab culture is the way of appeal internal values during cultivating university talents, and also a vital platform provided for developing top talents. However, the practical function has yet come into play. Some labs are in a lack of the viewpoint of educating people through lab culture, some have neglected the function of it, and some even deviated from the basic requirements of cultural education. The talent cultivation in labs places too much importance in "become a professional talent" in education, while makes light of "become a useful person", which means that they overemphasis the improvement of students in professional ability and scientific level, and at the same time neglect the possibility of their comprehensive development. The target of talent cultivation has simplified as directing by scientific research. In order to ensure students have abundant time and energy to devote themselves to scientific research study, regulators may restrict their students from taking part in any non-professional education for improving the comprehensive quality. Because of short in scientific regulations of lab evaluation index system, there exists the phenomena of seeking quick success and instant benefits, pursuing excessively the realization of extrinsic material condition and the acquisition of honorary position as well as quantifiable index. All these may foster students the ethos of going after fame and money and also being unsettled and short-tempered. Thus those students will be difficult in form well character and morals, ideology, willpower and emotion, and their behavior and personal integrity. Most of the management system in labs is compulsory order, in that many viewpoints with individual originality had been neglected and limited because students are afraid of making mistakes and against rules. Unable to seize the opportunity to practice themselves has at certain extent dampen their enthusiasm.

\section{Deficient in Laboratorial Internal Innovative Culture}

As a platform to cultivating university talents, lab is the core production area of breeding scientific research innovation and efforts, which is responsible for studying national science technology and supporting regional economy construction. But compared with foreign world-class universities, China's university labs are in a lack of original creativity and scientific research efforts. The low rate of contribution of laboratorial scientific research in China failed to form an effective innovation system. At large extent, it is because of the deficient in laboratorial internal innovative culture. Firstly, during the establishment of lab material culture, there isn't enough exploration of the external environment for encouraging students' creativity, then without innovative spiritual carrier that can materialization in the labs' interior decoration, and finally lacking of full and effective communication platform among lab members. Secondly, labs need the atmosphere that can fostering innovative spirit and the concept of innovative culture. Without sufficient soft environment creativity, such as free and comprehensive, innovation encouraging, and individuality developing, the courage that unafraid of failure and dare to bear it, the boldness that unafraid of public opinion and dare to have a try, and the mind that can contain and understand innovation failure are all lacking in labs. Thirdly, the system management level emphasizes the target management and quantization management while neglect the human-oriented management. The human-oriented concern is scarce in the formulation and execution of rules. What's more, the attention on individual requirement and development is not enough, thus it can't stimulate the interior need of independent innovation effectively.

\section{WAY OF BUILDING THE LABORATORIAL CULTURE UNDER THE CIRCUMSTANCE OF "DOUBLE- FIRST- CLASS"}

First-rate laboratorial culture is the strong soft power to strengthen lab cultural confidence and build excellent labs, and it's also the connotation of "Double First-class" construction. In the new era, excellent lab culture is structured imperatively to lead the building of first-class labs and promoting the process of "Double First-class".

\section{A. Pay High Attention to the Building of Laboratorial Culture}

\section{1) Arouse the Lab Cultural Self-consciousness}

The concept of "cultural self- consciousness", which is the thought crystal of scholar Fei Xiao-tong's academic introspection in his old age, refers to that the people live in certain culture have a "self-knowledge" of their own culture, and can make clear about its origin, forming process, as well as 
the role it plays in various aspects of life, i.e. their meaning, the impact from other culture and the development direction [8]. When recommending this concept into the lab cultural selfconsciousness, there are three details. First of all, lab members should have a clear and definite knowledge about the conception, features, functions and the role labs played in the cultural construction It is needed to highly emphasize the lab culture in promoting first-rate labs and the important position of "Double First-class" Initiative construction in thoughts. Next, basing upon those interior situations of labs such as professional research direction, subject characteristic and talent cultivation plan, then combining with exterior environment such as socialist core values, national culture, campus culture and other excellent lab culture both home and abroad, to form the specific cultural system of their own labs. Last but not least, after forming the characteristic cultural system, labs need to stand their ground of cultural self-consciousness, that means to have clear self-knowledge of their own lab cultural construction, and they should introspect the efforts and problems during the cultural construction combining with new constructive situation, together with comprehensive development plans and specific development direction.

\section{B. Confirm the Concept of Laboratorial Culture}

On the one hand, when formulating the concept of laboratorial culture, it must demonstrate the cultural features and conform to the intrinsic requirement of "Double Firstclass" Initiative construction. Different lab culture may have certain differences regionally, however, excellent lab culture share some same traits. To form outstanding lab culture, labs should grasp the spiritual core of "Double First-class" Initiative deeply, with first-class cultural spirit and then develop the characteristic cultural concept mixing together labs' own practical condition. On the other hand, labs can ascertain some core cultural conception which with high generality and powerful guiding function, blending in some designs like lab symbols, mottos, missions, and visions. It may express the talent cultivation as well as every lab works required by the first-class lab construction concisely and suggest its guiding function to individual behavior that lab members set it as standard to constantly introspect whether their own words and behaviors conform to the education requirement of cultural concepts.

\section{Intensify the Education Function of Laboratorial Culture}

\section{1) To integrate quality-oriented education culture}

The quality-oriented education culture should run through the professional education and the non-professional education all the time. The fundamental purpose of the quality-oriented education culture is to realize the harmonious development of the individual's comprehensive quality. We should focus on the students' professional education of scientific research, and we need to pay more attention to enhance their social adaptability. Firstly, the educators should consciously integrate the humanistic spirit and scientific spirit into professional courses and practice courses and pay attention to the cultural infiltration of quality-oriented education so as to improve the students' own cultural quality. The educators should also focus on the students' psychological health education to give students an appropriate setback education in the experiment teaching, and to let them learn to treat the success and failure in the experiment correctly. Secondly, we can integrate humanistic education and moral education to carry out rich and various activities, social practice and public benefit activities, which can give students the space to develop their interests and enhance students' moral quality, humanistic spirit, responsibility consciousness and patriotism.

\section{2) To establish good academic atmosphere}

A top-ranking laboratory must have a first-class academic environment. In the concept of consciousness, we should pay attention to cultivate members' cooperation consciousness, attitude to hard work for scientific research and solid and steady scientific style to convey a progressive academic spirit. In practice construction, we need to increase the academic atmosphere publicity, mainly including the advanced deeds of outstanding researchers, frontier trends in scientific research, the achievements of laboratory research work, information of academic exchange reports and so on. In addition, we need to organize multiform and multilevel academic exchange activities, and build a platform for communications among lab members, different laboratories, schools, multidisciplinary and cross-disciplinary fields. In particular, we should strengthen academic dialogue with world-class universities.

\section{3) To realize humanized management}

To realize the humanization of the system management mode, we must make it clear that the focus of management should change from human behavior to the promotion of people's ideas and values. To optimize the laboratory personnel training evaluation system, to adhere to the diversification principles of evaluation subject, indicator content and method, and to focus on the evaluation of members' development. To strengthen the cultural construction of "laboratory roommate", to merge humanized management into the laboratory talent cultivation and to play the role of excellent laboratory culture in continuously affecting the members' spirit and emotional implication. We can make it as a strong link to University alumni culture construction to actively promote the formation of first-class university culture.

\section{Create the Roots of Innovative Culture}

\section{1) To form cognitive concept guided by innovation}

To establish the concept of "innovation is the foundation of the laboratory", and to fundamentally understand the core position of innovation, especially the original innovation, in the construction of first-class laboratory and individual development. We need to pay attention to the guiding and stimulating effect of the flexible factors of thoughts and values, to enhance the soft environment construction of innovative culture, and to strive to construct the group common cognition and value with the characteristics of respecting individuality, focusing on rational criticism, making practice as the source, trying with no fear, being tolerant to failure and cooperating so as to build good innovative cultural atmosphere. To correct the misunderstanding of innovation quality, to clear the scientific literacy, humanistic quality, psychological quality and other conditions required for innovative quality. In dealing with the attitude to the innovative thinking and innovative results, we should stick to the dual direction of process and results. 


\section{2) To enrich the construction of material culture}

To use external environment to create the materialization of innovative culture and to make "celebrity culture on wall" play the exemplary role in stimulating students' innovative spirit. To actively utilize creative external space layout and design with features to achieve the visualization of innovative material culture construction. To creatively build online and offline multidimensional platform, which are database management platform established with the Internet as a method, open academic exchange platform based on project display window and special academic report, mutual practice operating platform oriented by interest and the international platform for sharing information in academic frontier and first-class disciplinary development. Especially in the background of the "Internet +" era, we need to actively develop a variety of online communication channels, such as laboratory website construction, micro-blog, WeChat, forums and so on. All of which will be made as space platform for members to display innovation and entrepreneurship and to share scientific research results and experiences so as to build bridge with high sufficiency and quality for members to exchange ideas and communicate with each other.

\section{3) To formulate rules for encouraging innovation system}

To integrate innovative ideas and innovative spirit into the development of laboratory system norms, to make innovation spirits transformed to a specific system requirements, and to ensure the innovation atmosphere will be created in an institutionalized way. To adhere to make the democratic management as the core and to improve the participation of laboratory members. To strengthen the management of innovation talent team, to set up a specialized team of innovation talent in the laboratory, and to make the core leaders and young talents having innovation potential as the main members. After forming a certain creative influence, the young talents should be cultivated as the backbone of a communication and construction of laboratory innovation culture. To establish a reasonable assessment mechanism to protect the specificity of the members in scientific research and innovation. To reward the people with significant innovation contribution, and to make the external system as a booster to invigorate innovation so as to give the members system protection to devote themselves to scientific research and innovation.

\section{CONCLUSION}

To achieve the construction and reform goal of "Double First-rate" of higher education in our country, we need to accelerate the construction of world-class exquisite laboratories. Under the background of "Double First-rate", the excellent laboratory culture plays an irreplaceable role in promoting laboratory's sustainable development, improving the quality of personnel training and helping form top-ranking university culture. Faced with the new trend of "Double First-rate" construction, the universities should attach great importance to the construction of laboratory culture, realize cultural and educational function of laboratory, firmly establish the laboratory innovation and cultural foundation and promote a rapid and sound development of laboratory culture construction and finally achieve the "Double First-rate" construction.

\section{REFERENCES}

[1] Ministry of Education. Overall Plan for Promotion Construction of the World-class Universities and First-class Discipline [Z].2015-10-24.

[2] Li Hai-yan, Qiao Dong. The spiritual culture of World-Class universities and its implications for China $[\mathrm{J}]$. Tsinghua Journal of Education,2009,(2):114-118.(In Chinese)

[3] Lu Shan. Analysis on the culture construction of key research institution [J]. Journal of Jiangsu Institute of Education(Natural Sciences),2009,(1):14-16.(In Chinese)

[4] Zhang Chun-ping, Chen Yong, Lu Hong-wei. Building and development of culture soft power in laboratory construction $[\mathrm{J}]$. Experimental Technology and Management,2012,(6):203-205.(In Chinese)

[5] Ministry of Education. Overall Plan for Promotion Construction of the World-class Universities and First-class Discipline [Z].2015-10-24.

[6] Lu Shan. Analysis on the culture construction of key research institution [J]. Journal of Jiangsu Institute of Education (Natural Sciences), 2009, (1):14-16.

[7] Liu Lin-tao, Tian Hui-zhen. Reform and development research of laboratory of universities [J]. China Modern Educational Equipment, 2013, (15):25-27.

[8] Fei Xiao-tong. Culture and cultural consciousness [M]. Beijing: Qunyan Publishing House, 2010, (8):182. 